Research Article

\title{
Finite Element Formulation for Stability and Free Vibration Analysis of Timoshenko Beam
}

\author{
Abbas Moallemi-Oreh ${ }^{1}$ and Mohammad Karkon ${ }^{2}$ \\ ${ }^{1}$ Department of Mechanical Engineering, Shahreza Branch, Islamic Azad University, Shahreza, Iran \\ ${ }^{2}$ Department of Civil Engineering, Ferdowsi University of Mashhad, Mashhad, Iran
}

Correspondence should be addressed to Mohammad Karkon; karkon443@gmail.com

Received 18 February 2013; Revised 1 April 2013; Accepted 1 April 2013

Academic Editor: K. M. Liew

Copyright (C) 2013 A. Moallemi-Oreh and M. Karkon. This is an open access article distributed under the Creative Commons Attribution License, which permits unrestricted use, distribution, and reproduction in any medium, provided the original work is properly cited.

\begin{abstract}
A two-node element is suggested for analyzing the stability and free vibration of Timoshenko beam. Cubic displacement polynomial and quadratic rotational fields are selected for this element. Moreover, it is assumed that shear strain of the element has the constant value. Interpolation functions for displacement field and beam rotation are exactly calculated by employing total beam energy and its stationing to shear strain. By exploiting these interpolation functions, beam elements' stiffness matrix is also examined. Furthermore, geometric stiffness matrix and mass matrix of the proposed element are calculated by writing governing equation on stability and beam free vibration. At last, accuracy and efficiency of proposed element are evaluated through numerical tests. These tests show high accuracy of the element in analyzing beam stability and finding its critical load and free vibration analysis.
\end{abstract}

\section{Introduction}

Two versions of theories have been developed for analysis of beams. In Euler-Bernoulli theory, the displacement of beam is considered without shear effects. This method gives appropriate and acceptable response in thin beam in which shear effect is insignificant. However, in this approach, by increasing the thickness of beam and shear effect deformation, the error of response is increasing [1]. Correspondingly, the effect of shear transformation is formulated in Timoshenko theory. Therefore, this method has a better result, especially in deep beams in which shear effect is impressive. Although the rotational inertia of thick beams was investigated by Rayleigh for the first time, Timoshenko has developed this theory and formulated shear effect. Due to the complexity of the governing equations of the free vibration and stability of beams in general, numerical methods such as finite element have been developed profoundly. Up to now, many elements have been presented based on Timoshenko theory. These elements are classified into two groups which are simple and higher order elements. Some researchers used simple two-node elements with four degrees of freedom [2-4]. Thomas et al. have examined the elements proposed by other researchers [3].
The first high-order element was proposed by Kapur with eight degrees of freedom [5]. Lees and Thomas formulated a complex element by applying independent polynomial series for displacement and rotation fields [6,7]. Also, this method has been used by Webster [8]. Rao and Gupta have examined free vibration of rotating beams [9]. In some methods, like isoparametric formulation, displacement and rotation fields are assumed dependently with the same order [10]. Based on Euler-Bernoulli theory, Goncalves et al. have presented frequency equation and vibration modes for classical boundary conditions such as clamped, free, pinned, and sliding supports [11]. Lee and Schultz have considered free vibration of Timoshenko beam through pseudospectral method [12].

So far, very little research has been done on buckling of Timoshenko beam with respect to free vibration analysis. Exploiting an approximate method based on finite elements formulation, Wieckowski and Golubiewski examined beam stability of Euler-Bernoulli and Timoshenko theories [13]. Also, Kosmatka has proposed a two-node element for stability and free vibration analysis of Timoshenko beam [14].

In this study, a new beam element is proposed for free vibration and stability analysis of Timoshenko beams. In order to compute shape function of the beam element, cubic 


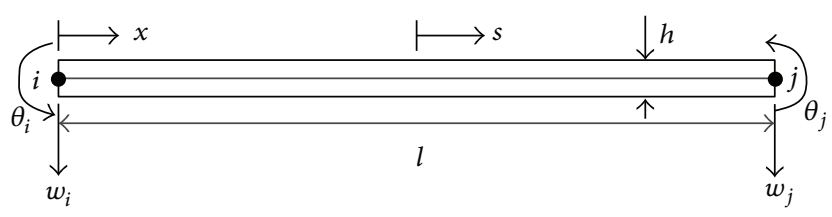

Figure 1: Timoshenko beam element.

displacement polynomial and quadratic rotational fields are selected. In addition, shear strain of the element is assumed constant. Then, by exploiting the bending and shear strain energy of the beam and stationary with respect to constant shear strain, interpolation function of this element has been carefully calculated. In the following, by using these shape functions, the stiffness matrix, geometric stiffness matrix, and mass matrix of the proposed element have been exactly determined. Finally, several numerical tests are performed to investigate the robustness of this element for free vibration and stability analysis of beams with different boundary conditions. The findings prove that the suggested element has high level of accuracy and free of shear locking.

\section{Finite Element Formulation}

In the finite element method, displacement and rotation fields of the element are associated with interpolation functions to nodal degrees of freedom. Figure 1 shows proposed element with two nodes. The shape functions of the Timoshenko beam are calculated based on Figure 1. In order to compute shape function of the beam in Figure 1, cubic displacement polynomial and quadratic rotational fields are selected. Additionally, it is assumed that shear strain has the constant value of $\gamma_{0}$. Based on these assumptions, (1) can be written as follows:

$$
\begin{gathered}
w=\frac{w_{i}}{2}(1-s)+\frac{w_{j}}{2}(1+s) \\
+\beta_{0} l\left(1-s^{2}\right)+\beta_{1} l s\left(1-s^{2}\right) \\
\theta=\frac{\theta_{i}}{2}(1-s)+\frac{\theta_{j}}{2}(1+s)+\alpha_{0}\left(1-s^{2}\right) \\
\gamma=\gamma_{0} \\
s=\frac{2 x}{l}-1 .
\end{gathered}
$$

In these equations, $\beta_{1}, \beta_{0}, \alpha_{0}$, and $\gamma_{0}$ are unknown parameters. In order to determine their values, at first, the equation of shear strain for Timoshenko beam is established. By utilizing the shear strain value equal to $\gamma_{0}$, the subsequent equations will be available:

$$
\begin{gathered}
\gamma=\frac{d w}{d x}-\theta=\frac{2}{l} \cdot \frac{d w}{d s}-\theta \\
\gamma_{0}=\frac{2}{l}\left(-\frac{w_{i}}{2}+\frac{w_{j}}{2}-2 \beta_{0} l s+\beta_{1} l-3 \beta_{1} l s^{2}\right) \\
-\theta_{i}\left(\frac{1-s}{2}\right)-\theta_{j}\left(\frac{1+s}{2}\right)-\alpha_{0}\left(1-s^{2}\right) .
\end{gathered}
$$

In the present formula, the coefficients of the terms $s$ and $s^{2}$ are equivalent to zero. Therefore, in the succeeding lines, $\alpha_{0}$, $\beta_{1}$ are determined in terms of the unknown parameter $\gamma_{0}$ :

$$
\begin{gathered}
\Gamma=\frac{2}{l}\left(w_{j}-w_{i}\right)-\left(\theta_{i}+\theta_{j}\right) \\
\beta_{0}=\frac{1}{8}\left(\theta_{i}-\theta_{j}\right) \\
\alpha_{0}=-\frac{3}{2}\left(\gamma_{0}-\frac{1}{2} \Gamma\right) \\
\beta_{1}=\frac{1}{6} \alpha_{0} .
\end{gathered}
$$

At this stage, there is only one unknown constant $\gamma_{0}$, which can be discovered through the condition of minimum strain energy. It should be added that the structural strain energy is the sum of bending and shear strain energy. Bending strain energy is calculated in the following way:

$$
U_{b}=\frac{E I}{2} \int_{0}^{l} \kappa^{2} d x=\frac{E I l}{4} \int_{-1}^{1} \kappa^{2} d s .
$$

In (4), $\kappa$ represents curvature which is determined as follows:

$$
\begin{aligned}
& \kappa=-\frac{2}{l} \cdot \frac{d \theta}{d s}=\kappa_{0}-6 \frac{s \gamma_{0}}{l} \\
& \kappa_{0}=\frac{1}{l}\left(\theta_{i}-\theta_{j}+3 s \Gamma\right) .
\end{aligned}
$$

Substituting (5) into (4) leads to the following bending strain energy:

$$
\begin{gathered}
U_{b}=U_{0}+6 E I\left(-\frac{\Gamma \gamma_{0}}{l}+\frac{\gamma_{0}^{2}}{l}\right) \\
U_{0}=\frac{E I l}{4} \int_{-1}^{1} \kappa_{0}^{2} d s .
\end{gathered}
$$

Besides, (7) shows the energy of shear strain:

$$
\begin{aligned}
U_{s} & =\frac{G A}{2 f_{s}} \int_{0}^{1} \gamma^{2} d x \\
& =\frac{G A l}{4 f_{s}} \int_{-1}^{1} \gamma_{0}^{2} d s \\
& =\frac{G A l}{2 f_{s}} \gamma_{0}^{2} .
\end{aligned}
$$

In this equation, $f_{s}$ is shear correction factor which depends on cross section shape of beam. This coefficient for rectangular section is $5 / 6$. By adding the bending and shear strain energy together, total strain energy is found as follows:

$$
U=U_{b}+U_{s}=U_{0}-\frac{6 E I \Gamma}{l} \gamma_{0}+\frac{6 E I}{l} \gamma_{0}^{2}+\frac{G A l}{2 f_{s}} \gamma_{0}^{2} .
$$

Implementing $\partial U / \partial \gamma_{0}=0$ will give the following results:

$$
\begin{aligned}
& \gamma_{0}=\frac{6 E I \Gamma}{G A l^{2} / f_{s}+12 E I}=\delta \Gamma \\
& \delta=\frac{6 \lambda}{l^{2}+12 \lambda}, \quad \lambda=\frac{f_{s} E I}{G A} .
\end{aligned}
$$


Substituting $\beta_{1}, \beta_{0}, \alpha_{0}$, and $\gamma_{0}$ into (1), the succeeding shape functions for Timoshenko beam can be as follows:

$$
\begin{aligned}
& \left\{\begin{array}{c}
\widetilde{w} \\
\widetilde{\theta}_{n}
\end{array}\right\}=\left[\begin{array}{llll}
N_{1} & N_{2} & N_{3} & N_{4} \\
N_{5} & N_{6} & N_{7} & N_{8}
\end{array}\right]\left\{\begin{array}{c}
w_{i} \\
\theta_{n i} \\
w_{j} \\
\theta_{n j}
\end{array}\right\} \\
& N_{1}=\frac{1}{4}\left[2+s^{3}(1-2 \delta)+s(-3+2 \delta)\right] \\
& N_{2}=\frac{l}{4}\left[0.5\left(1-s^{2}\right)+\left(s^{3}-s\right)(0.5-\delta)\right] \\
& N_{3}=\frac{1}{4}\left[2-s^{3}(1-2 \delta)-s(-3+2 \delta)\right] \\
& N_{4}=\frac{l}{4}\left[-0.5\left(1-s^{2}\right)+\left(s^{3}-s\right)(0.5-\delta)\right] \\
& N_{5}=\frac{1}{4 l}\left[6\left(1-s^{2}\right)(-1+2 \delta)\right] \\
& N_{6}=\frac{1}{4}\left[-1+s(-2+3 s)+6\left(1-s^{2}\right) \delta\right] \\
& N_{7}=\frac{1}{4 l}\left[-6\left(1-s^{2}\right)(-1+2 \delta)\right] \\
& N_{8}=\frac{1}{4}\left[-1+s(2+3 s)+6\left(1-s^{2}\right) \delta\right] \text {. }
\end{aligned}
$$

In finite element method, displacements and strain field of the element can be related to the nodal degrees of freedom with interpolation functions. Hence, equations of finite element formulation can be written as follows:

$$
\begin{gathered}
\left\{\begin{array}{l}
y \\
\theta
\end{array}\right\}=[N]\{D\}_{E} \\
\{\varepsilon\}=\left\{\begin{array}{c}
\frac{d y}{d x} \\
-\frac{d y}{d x}+\theta
\end{array}\right\}=[B]\{D\}_{E},
\end{gathered}
$$

where

$$
[B]=\left[\begin{array}{cc}
0 & \frac{d}{d x} \\
\frac{d}{d x} & -1
\end{array}\right][N]
$$

and $[N]$ is the matrix of interpolation function. Also, $\{D\}_{E}$ is nodal displacement and $[B]$ is strain matrix. Consequently, stiffness matrix of Timoshenko element can be obtained as follows:

$$
\left[K_{0}\right]=\int[B]^{T}\left[D_{m}\right][B] d x,
$$

where, $\left[D_{m}\right]$ is the elasticity matrix for Timoshenko beam element:

$$
\left[D_{m}\right]=\left[\begin{array}{cc}
E I & 0 \\
0 & \frac{G A}{f_{s}}
\end{array}\right]
$$

By calculating (13), the stiffness matrix of the proposed element is obtained in the succeeding forms:

$$
\begin{aligned}
{\left[K_{0}\right]=} & \frac{E I}{l^{3}+12 l \lambda} \\
& \times\left[\begin{array}{cccc}
12 & 6 l & -12 & 6 l \\
6 l & 4 l^{2}+12 \lambda & -6 l & 2 l^{2}-12 \lambda \\
-12 & -6 l & 12 & -6 l \\
6 l & 2 l^{2}-12 \lambda & -6 l & 4 l^{2}+12 \lambda
\end{array}\right]
\end{aligned}
$$

\section{Mass Matrix}

The kinetic energy, $T$, of an elemental length, $l$, of a uniform Timoshenko beam is given as follows [1]:

$$
T=\frac{1}{2} \int_{-l / 2}^{l / 2} \rho A \dot{y}^{2} d x+\frac{1}{2} \int_{-l / 2}^{l / 2} \rho I \dot{\theta}^{2} d x
$$

In this equation, $\rho$ is the mass density of the material of the beam and $I$ is the second moment of area of cross section. Therefore, the mass matrix of the element has been two parts, one related to translations and the other related to rotations, in the form of

$$
\begin{aligned}
{[M]=} & {\left[M_{1}\right]+\left[M_{2}\right] } \\
= & \frac{l}{2} \int_{1}^{1} \rho A\left[N_{w}\right]^{T}\left[N_{w}\right] d s \\
& +\frac{l}{2} \int_{-l / 2}^{l / 2} \rho I\left[N_{\theta}\right]^{T}\left[N_{\theta}\right]^{T} d s .
\end{aligned}
$$

The translation mass matrix $\left[M_{1}\right]$ is achieved as follows:

$$
\begin{aligned}
{\left[M_{1}\right]=} & \frac{\rho A l^{5}}{210\left(12 \lambda+l^{2}\right)^{2}} \\
& \times\left[\begin{array}{cccc}
m_{11} & m_{12} & m_{13} & m_{14} \\
m_{12} & m_{15} & -m_{14} & m_{16} \\
m_{13} & -m_{14} & m_{11} & -m_{12} \\
m_{14} & m_{16} & -m_{12} & m_{15}
\end{array}\right] .
\end{aligned}
$$

In the following, the entries of this matrix are introduced:

$$
\begin{aligned}
& m_{11}=\frac{6}{l^{4}}\left(1680 \lambda^{2}+294 l^{2} \lambda+13 l^{4}\right) \\
& m_{12}=\frac{1}{l^{3}}\left(1260 \lambda^{2}+231 l^{2} \lambda+11 l^{4}\right) \\
& m_{13}=\frac{9}{l^{4}}\left(560 \lambda^{2}+84 l^{2} \lambda+3 l^{4}\right) \\
& m_{14}=-\frac{1}{2 l^{3}}\left(2520 \lambda^{2}+378 l^{2} \lambda+13 l^{4}\right) \\
& m_{15}=\frac{2}{l^{2}}\left(126 \lambda^{2}+21 l^{2} \lambda+13 l^{4}\right) \\
& m_{16}=-\frac{3}{2 l^{2}}\left(168 \lambda^{2}+28 l^{2} \lambda+13 l^{4}\right) .
\end{aligned}
$$


In addition, the rotation mass matrix $\left[M_{2}\right]$ can be obtained as follows:

$$
\begin{aligned}
{\left[M_{2}\right]=} & \frac{\rho I l^{2}}{30\left(12 \lambda+l^{2}\right)^{2}} \\
& \times\left[\begin{array}{cccc}
m_{21} & m_{22} & -m_{21} & m_{22} \\
m_{22} & m_{23} & -m_{22} & m_{24} \\
-m_{21} & -m_{22} & m_{21} & -m_{12} \\
m_{22} & m_{24} & -m_{12} & m_{23}
\end{array}\right] .
\end{aligned}
$$

The entries of this matrix are defined in the below form:

$$
\begin{aligned}
& m_{21}=36 l \\
& m_{22}=-3\left(60 \lambda-l^{2}\right) \\
& m_{23}=\frac{4}{l}\left(360 \lambda^{2}+15 l^{2} \lambda+3 l^{4}\right) \\
& m_{24}=\frac{1}{l}\left(720 \lambda^{2}-60 l^{2} \lambda-l^{4}\right) .
\end{aligned}
$$

\section{Geometric Stiffness Matrix}

The concept of the neutral state of equilibrium is used for buckling analysis of beam. In the mathematical formulation of elastic stability of beam, the neutral equilibrium is used assuming a bifurcation of the deformations. That is, at the critical load, of the possible two paths of deformations (one associated with the stable equilibrium and the other pertinent to the unstable equilibrium condition, as shown in Figure 2), the beam always takes the buckled form. In addition to the existence of this bifurcation of equilibrium paths, the elastic stability analysis of plates assumes the validity of Hooke's law. By considering Figure 2 at the buckled form, the axial shortening of beam can be acquired as follows:

$$
\begin{aligned}
d s & =\sqrt{\left(d x^{2}+d y^{2}\right)} \\
& \simeq d x+\frac{1}{2}\left(\frac{d y}{d x}\right)^{2} d x \\
& \Longrightarrow d \delta=\frac{1}{2}\left(\frac{d y}{d x}\right)^{2} d x .
\end{aligned}
$$

As a result, the strain energy of axial load $P$ can be expressed as follows:

$$
\Delta W=\frac{P}{2} \int_{0}^{l}\left(\frac{d y}{d x}\right)^{2} d x
$$

Based on (23), geometric stiffness matrix of the element can be calculated as follows:

$$
\left[K_{g}\right]=\int_{0}^{l}\left[\frac{d N_{w}}{d x}\right]^{T} P\left[\frac{d N_{w}}{d x}\right] d x .
$$

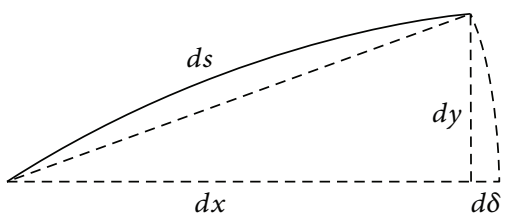

FIGURE 2: Straight and buckled form.

By calculating this equation, the geometric stiffness matrix becomes as follows:

$$
\begin{aligned}
{\left[K_{g}\right]=} & \frac{P}{60 l} \\
& \times\left[\begin{array}{cccc}
k_{g 1} & k_{g 2} & k_{g 3} & k_{g 2} \\
k_{g 2} & k_{g 4} & -k_{g 2} & k_{g 5} \\
k_{g 3} & -k_{g 2} & k_{g 1} & -k_{g 2} \\
k_{g 2} & k_{g 5} & -k_{g 2} & k_{g 4}
\end{array}\right],
\end{aligned}
$$

where

$$
\begin{aligned}
& k_{g 1}=60+12 \beta \\
& k_{g 2}=6 \beta l \\
& k_{g 3}=-60-12 \beta \\
& k_{g 4}=5 l^{2}+3 \beta l^{2} \\
& k_{g 5}=3 \beta l^{2}-5 l^{2} \\
& \beta=\frac{l^{4}}{\left(l^{2}+12 \lambda\right)^{2}} .
\end{aligned}
$$

For stability analysis and determination of the magnitude of a static compressive axial load that will produce beam buckling, the following eigenvalue will be achieved:

$$
\operatorname{det}([K])=\operatorname{det}\left(\left[K_{0}\right]-P\left[K_{g}\right]\right)=0 \Longrightarrow P_{\mathrm{cr}} \text {. }
$$

The lowest positive eigenvalue of this equation is the magnitude of buckling load and the corresponding eigenvector is the deformed shape of the buckled beam. The exact solution of beam-column buckling load with shear deformation effect is obtained as succeeding form [15]:

$$
\begin{aligned}
P_{\mathrm{cr}}= & \frac{\pi^{2} E I}{L_{\mathrm{eff}}^{2}} \\
& \times\left(\frac{1}{1+\left(\pi^{2} f_{s} E I\right) /\left(L_{\mathrm{eff}}^{2} G A\right)}\right),
\end{aligned}
$$

where $L_{\text {eff }}$ is the effective beam length in which $\left(L_{\text {eff }}=L\right)$ and $\left(L_{\text {eff }}=L / 2\right)$ are used for pinned-pinned beams and fixedfixed beams, respectively.

4.1. First Example (Vibration Analysis). The efficiency of proposed element is evaluated by analyzing the free vibration of beam with simply and clamped supports for various 
TABLE 1: Dimensionless frequency parameter $\lambda_{i}$ for the simply supported Timoshenko beam.

\begin{tabular}{lcccc}
\hline Mode & Euler theory & & $h / l=0.002$ & \\
& & Ferreira [10] & Lee and Schultz [12] & 3.14158 \\
1 & 3.14159 & 3.1428 & 3.14158 & 6.28310 \\
2 & 6.28319 & 6.2928 & 6.28310 & 9.42450 \\
3 & 9.42478 & 9.4573 & 9.42449 & 12.5657 \\
4 & 12.5664 & 12.6437 & 12.5657 & 15.7068 \\
5 & 15.7080 & 15.8596 & 15.7066 & 18.8476 \\
6 & 18.8496 & 19.1127 & 18.8473 & 21.9883 \\
7 & 21.9911 & 22.4113 & 21.9875 & 25.1288 \\
8 & 25.1327 & 25.7638 & 25.1273 & 28.2692 \\
9 & 28.2743 & 29.1793 & 28.2666 & 31.4098 \\
10 & 31.4159 & 32.6672 & 31.4053 & \\
\hline
\end{tabular}

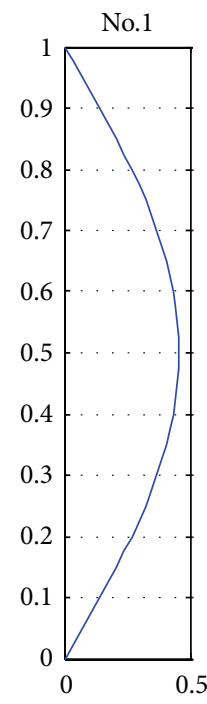

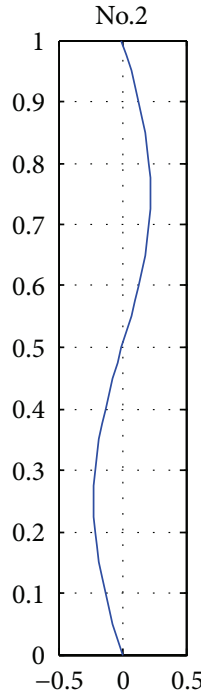

(a)
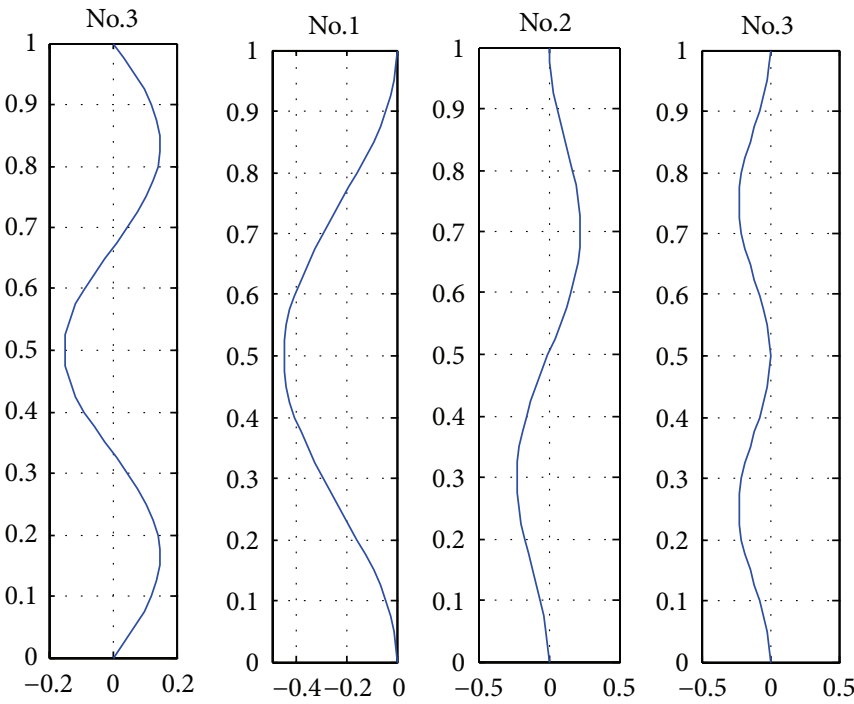

(b)

FIGURE 3: The first three modes of buckling for beam-column, (a) simply supported and (b) clamped supported.

TABLE 2: Dimensionless frequency parameter $\lambda_{i}$ for the simply supported Timoshenko beam.

\begin{tabular}{|c|c|c|c|c|}
\hline \multirow{2}{*}{ Mode } & \multirow{2}{*}{ Euler theory } & \multicolumn{3}{|c|}{$h / l=0.01$} \\
\hline & & Ferreira [10] & Lee and Schultz [12] & Proposed element \\
\hline 1 & 3.14159 & 3.1425 & 3.14133 & 3.14133 \\
\hline 2 & 6.28319 & 6.2908 & 6.28106 & 6.28106 \\
\hline 3 & 9.42478 & 9.4503 & 9.41761 & 9.41764 \\
\hline 4 & 12.5664 & 12.6271 & 12.5494 & 12.5496 \\
\hline 5 & 15.7080 & 15.8267 & 15.6749 & 15.6754 \\
\hline 6 & 18.8496 & 19.0552 & 18.7926 & 18.7937 \\
\hline 7 & 21.9911 & 22.3186 & 21.9011 & 21.9034 \\
\hline 8 & 25.1327 & 25.6231 & 24.9988 & 25.0034 \\
\hline 9 & 28.2743 & 28.9749 & 28.0845 & 28.0927 \\
\hline 10 & 31.4159 & 32.3806 & 31.1568 & 31.1705 \\
\hline
\end{tabular}


TABLE 3: Dimensionless frequency parameter $\lambda_{i}$ for the simply supported Timoshenko beam.

\begin{tabular}{|c|c|c|c|c|}
\hline \multirow{2}{*}{ Mode } & \multirow{2}{*}{ Euler theory } & \multicolumn{3}{|c|}{$h / l=0.1$} \\
\hline & & Ferreira [10] & Lee and Schultz [12] & Proposed element \\
\hline 1 & 3.14159 & 3.1169 & 3.11568 & 3.11569 \\
\hline 2 & 6.28319 & 6.0993 & 6.09066 & 6.09094 \\
\hline 3 & 9.42478 & 8.8668 & 8.84052 & 8.84229 \\
\hline 4 & 12.5664 & 11.3984 & 11.3431 & 11.3492 \\
\hline 5 & 15.7080 & 13.7089 & 13.6132 & 13.6282 \\
\hline 6 & 18.8496 & 15.8266 & 15.6790 & 15.7093 \\
\hline 7 & 21.9911 & 17.7811 & 17.5705 & 17.6239 \\
\hline 8 & 25.1327 & 19.5991 & 19.3142 & 19.3997 \\
\hline 9 & 28.2743 & 21.3030 & 20.9325 & 21.0606 \\
\hline 10 & 31.4159 & 22.9117 & 22.4441 & 22.6257 \\
\hline
\end{tabular}

TABLE 4: Dimensionless frequency parameter $\lambda_{i}$ for the clamped supported Timoshenko beam.

\begin{tabular}{|c|c|c|c|c|}
\hline \multirow{2}{*}{ Mode } & \multirow{2}{*}{ Euler theory } & \multicolumn{3}{|c|}{$h / l=0.002$} \\
\hline & & Ferreira [10] & Lee and Schultz [12] & Proposed element \\
\hline 1 & 4.73004 & 4.7345 & 4.72998 & 4.72998 \\
\hline 2 & 7.85320 & 7.8736 & 7.85295 & 7.85296 \\
\hline 3 & 10.9956 & 11.0504 & 10.9950 & 10.9950 \\
\hline 4 & 14.1372 & 14.2526 & 14.1359 & 14.1360 \\
\hline 5 & 17.2788 & 17.4888 & 17.2766 & 17.2768 \\
\hline 6 & 20.4204 & 20.7670 & 20.4168 & 20.4174 \\
\hline 7 & 23.5619 & 24.0955 & 23.5567 & 23.5578 \\
\hline 8 & 26.7035 & 27.4833 & 26.6960 & 26.6980 \\
\hline 9 & 29.8451 & 30.9398 & 29.8348 & 29.8382 \\
\hline 10 & 32.9867 & 34.4748 & 32.9729 & 32.9786 \\
\hline
\end{tabular}

TABLE 5: Dimensionless frequency parameter $\lambda_{i}$ for the clamped supported Timoshenko beam.

\begin{tabular}{lcccc}
\hline Mode & Euler theory & & $\begin{array}{c}h / l=0.01 \\
\text { Lee and } \\
\text { Schultz } \\
{[12]}\end{array}$ & $\begin{array}{c}\text { Proposed } \\
\text { element }\end{array}$ \\
\hline 1 & 4.73004 & 4.7330 & 4.72840 & 4.72840 \\
2 & 7.85320 & 7.8675 & 7.84690 & 7.84692 \\
3 & 10.9956 & 11.0351 & 10.9800 & 10.9801 \\
4 & 14.1372 & 14.2218 & 14.1062 & 14.1064 \\
5 & 17.2788 & 17.4342 & 17.2246 & 17.2253 \\
6 & 20.4204 & 20.6783 & 20.3338 & 20.3355 \\
7 & 23.5619 & 23.9600 & 23.4325 & 23.4358 \\
8 & 26.7035 & 27.2857 & 26.5192 & 26.5253 \\
9 & 29.8451 & 30.6616 & 29.5926 & 29.6032 \\
10 & 32.9867 & 34.0944 & 32.6514 & 32.6687 \\
\hline
\end{tabular}

lengths to thickness ratio. The Poisson's ratio of this beam is $v=0.3$ and shear correction factor is taken $5 / 6$.
TABLE 6: Dimensionless frequency parameter $\lambda_{i}$ for the clamped supported Timoshenko beam.

\begin{tabular}{lcccc}
\hline Mode & Euler theory & & $\begin{array}{c}h / l=0.1 \\
\text { Lee and } \\
\text { Schultz } \\
{[12]}\end{array}$ & $\begin{array}{c}\text { Proposed } \\
\text { element }\end{array}$ \\
\hline 1 & 4.73004 & 4.5835 & 4.57955 & 4.57962 \\
2 & 7.85320 & 7.3468 & 7.33122 & 7.33193 \\
3 & 10.9956 & 9.8924 & 9.85611 & 9.85918 \\
4 & 14.1372 & 12.2118 & 12.1454 & 12.1540 \\
5 & 17.2788 & 14.3386 & 14.2324 & 14.2513 \\
6 & 20.4204 & 16.3046 & 16.1487 & 16.1841 \\
7 & 23.5619 & 18.1375 & 17.9215 & 17.9807 \\
8 & 26.7035 & 19.8593 & 19.5723 & 19.6641 \\
9 & 29.8451 & 21.4875 & 21.1185 & 21.2523 \\
10 & 32.9867 & 23.0358 & 22.5735 & 22.7598 \\
\hline
\end{tabular}

To compare other researchers' results, frequency dimensionless parameter $\lambda_{i}$, defined in (29), has been shown in 
TABLE 7: Critical load of the simply and clamped supported beam-column.

\begin{tabular}{lcccccr}
\hline$l / h$ & & Simply supported & & \multicolumn{3}{c}{ Clamped supported } \\
& Analytical solution & Ferreira [10] & Proposed element & Analytical solution & Ferreira [10] & Proposed element \\
\hline 10 & 8013.8 & 8021.8 & 8013.86 & 29766 & 29877 & 29770 \\
100 & 8.223 & 8.231 & 8.2225 & 32.864 & 32.999 & 32.864 \\
1000 & 0.0082 & 0.0082 & 0.00822 & 0.0329 & 0.0330 & 0.0329 \\
\hline
\end{tabular}

(Tables 1, 2, 3, 4, 5, and 6) for 10 first frequencies of this beam by exploiting 40 elements:

$$
\lambda_{i}^{2}=\omega_{i} l^{2} \sqrt{\frac{\rho A}{E I}}
$$

Tables 1, 2, 3, and 4, 5, 6 show dimensionless parameters of natural frequency of beam-free vibration for simply and clamped supports, respectively, considering three ratios of thickness to length. Results have been compared to other researchers' studies. The mentioned tables demonstrate that the accuracy of the proposed element is very high in analyzing free vibration of beam.

4.2. Second Example (Buckling Analysis). The efficiency of the proposed element is determined in buckling analysis. For this propose, critical load of a simply and clamped supported beam-column is computed. The modulus of elasticity, Poisson's ratio, and length of this beam-column are $E=10 e 7, v=$ $1 / 3$, and $l=1$, respectively. The buckling loads of simply and clamped supported beam-columns are listed in Table 7. It demonstrates that the proposed element has high accuracy in buckling analysis. Figure 3 shows the first three modes of buckling for simply and clamped supported beam-column, respectively.

\section{Conclusion}

This study has proposed a new beam finite element formulation for the stability and free vibration analysis of beams with shear effect deformation. For this purpose, displacement field of the element has been selected from the third degree, rotation field has been selected from the second degree, and shear strain is assumed constant value. By employing the bending and shear strain energy of the element and stationary respect to unknown shear strain, this value is obtained. In the following, using the shear strain, the interpolation functions for displacement, and rotation fields of element has been exactly calculated. Then, these interpolation functions have been used and stiffness matrix, geometric stiffness matrix, and mass matrix of the proposed element have been clearly obtained. Evaluating the efficiency and accuracy of the element for free vibration and stability analysis of beam with simply and clamped supports, desirable results are obtained. The results show high accuracy and efficiency of the proposed element in calculating natural frequencies and critical load of beam with different boundary conditions.

\section{References}

[1] M. Petyt, Introduction of Finite Element Vibration Analysis, Cambridge University Press, 2nd edition, 2010.

[2] R. E. Nickel and G. A. Secor, "Convergence of consistently derived Timoshenko beam finite elements," International Journal for Numerical Methods in Engineering, vol. 5, no. 2, pp. 243$252,1972$.

[3] D. L. Thomas, J. M. Wilson, and R. R. Wilson, "Timoshenko beam finite elements," Journal of Sound and Vibration, vol. 31, no. 3, pp. 315-330, 1973.

[4] D. J. Dawe, "A finite element for the vibration analysis of Timoshenko beams," Journal of Sound and Vibration, vol. 60, no. 1, pp. 11-20, 1978.

[5] K. K. Kapur, "Vibrations of a Timoshenko beam using finite element approach," Journal of the Acoustical Society of America, vol. 40, pp. 1058-1063, 1966.

[6] A. W. Lees and D. L. Thomas, "Unified Timoshenko beam finite element," Journal of Sound and Vibration, vol. 80, no. 3, pp. 355366, 1982.

[7] A. W. Lees and D. L. Thomas, "Modal hierarchical Timoshenko beam finite elements," Journal of Sound and Vibration, vol. 99, no. 4, pp. 455-461, 1985.

[8] J. J. Webster, "Free vibrations of shells of revolution using ring finite elements," International Journal of Mechanical Sciences, vol. 9, no. 8, pp. 559-570, 1967.

[9] S. S. Rao and R. S. Gupta, "Finite element vibration analysis of rotating timoshenko beams," Journal of Sound and Vibration, vol. 242, no. 1, pp. 103-124, 2001.

[10] A. J. M. Ferreira, MATLAB Codes for Finite Element Analysis, Springer, 2008.

[11] P. J. P. Goncalves, M. J. Brennan, and S. J. Elliott, "Numerical evaluation of high-order modes of vibration in uniform EulerBernoulli beams," Journal of Sound and Vibration, vol. 301, pp. 1035-1039, 2007.

[12] J. Lee and W. W. Schultz, "Eigenvalue analysis of Timoshenko beams and axisymmetric Mindlin plates by the pseudospectral method," Journal of Sound and Vibration, vol. 269, no. 3-5, pp. 609-621, 2004.

[13] Z. Wieckowski and M. Golubiewski, "Improvement in accuracy of the finite element method in analysis of stability of EulerBernoulli and Timoshenko beams," Thin-Walled Structures, vol. 45, no. 10-11, pp. 950-954, 2007.

[14] J. B. Kosmatka, "An improved two-node finite element for stability and natural frequencies of axial-loaded Timoshenko beams," Computers and Structures, vol. 57, no. 1, pp. 141-149, 1995.

[15] B. Z. P. Bazant and L. Cedolin, Stability of Structures, Oxford University Press, New York, NY, USA, 1991. 

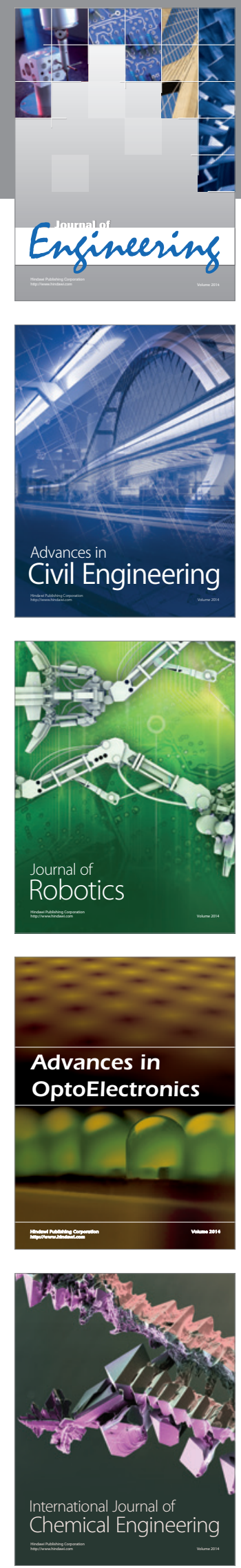

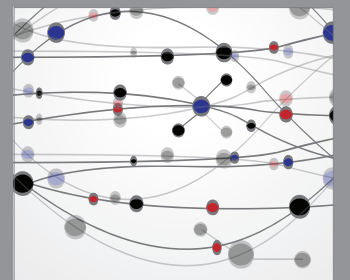

The Scientific World Journal
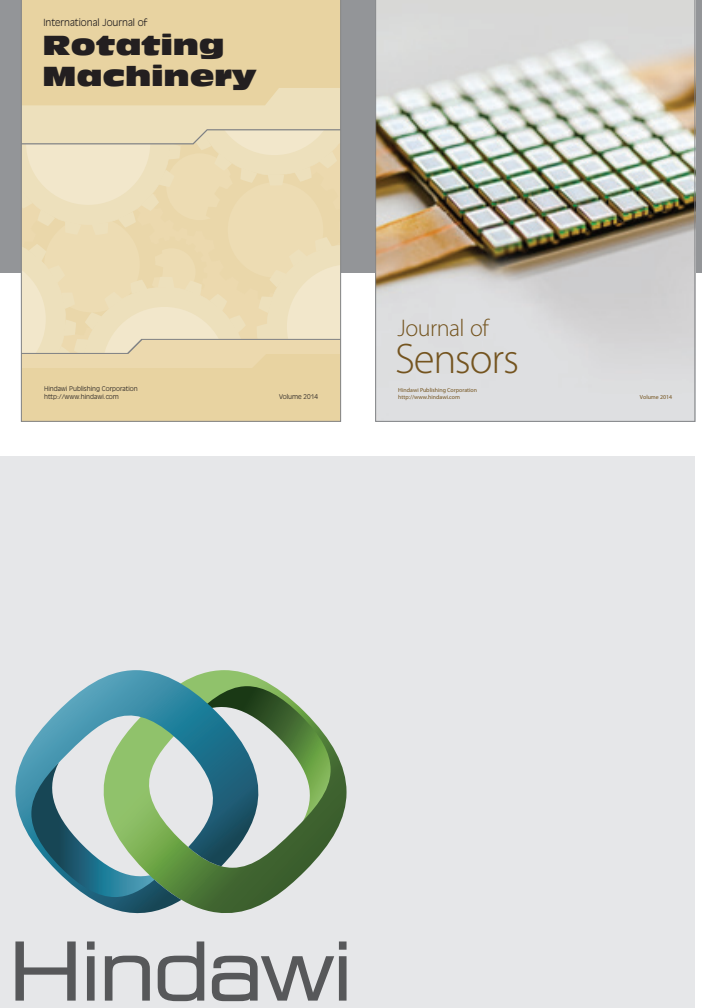

Submit your manuscripts at http://www.hindawi.com
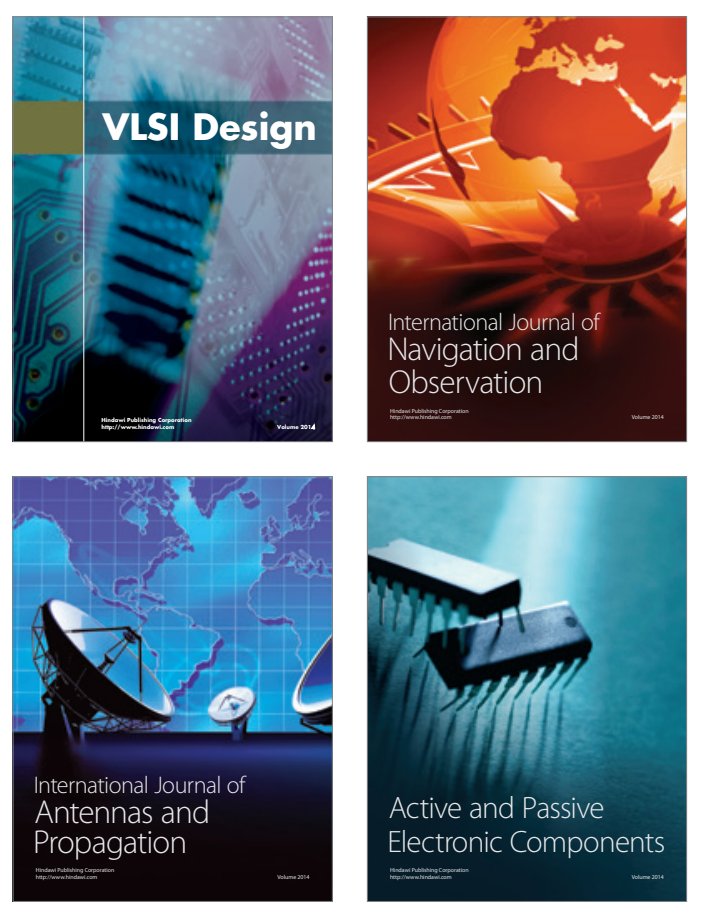
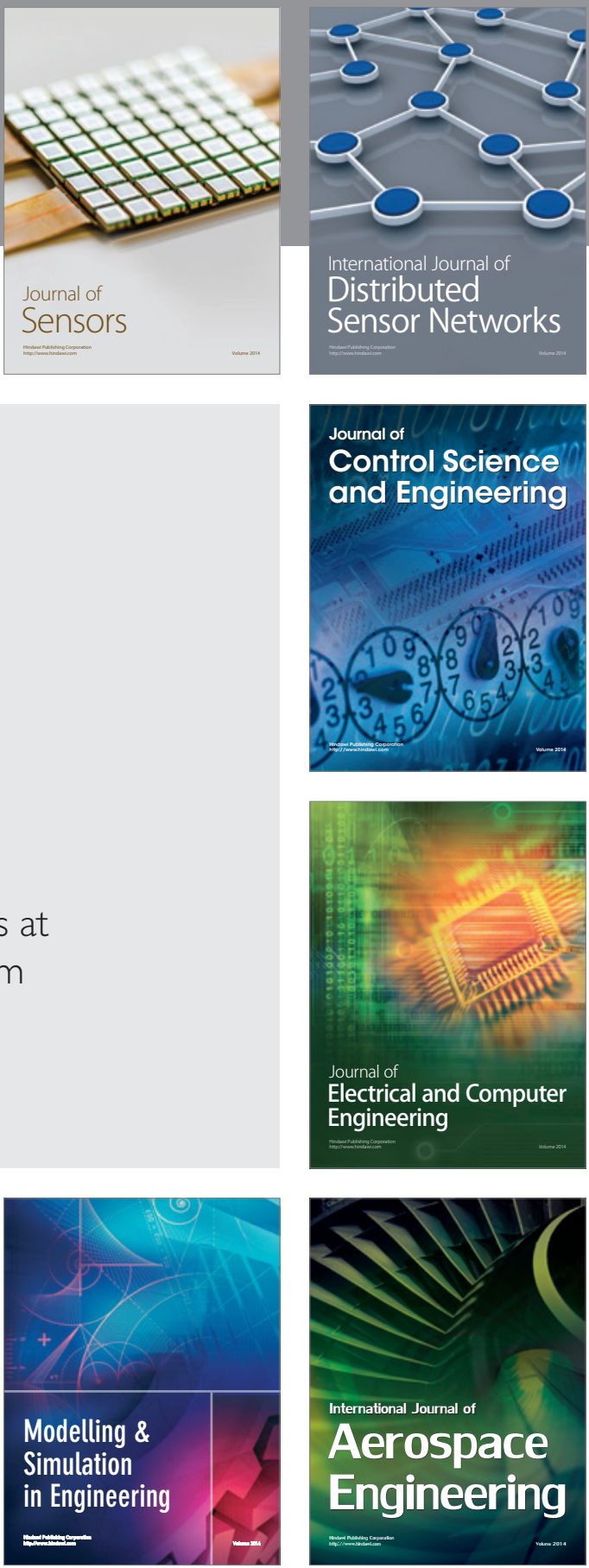

Journal of

Control Science

and Engineering
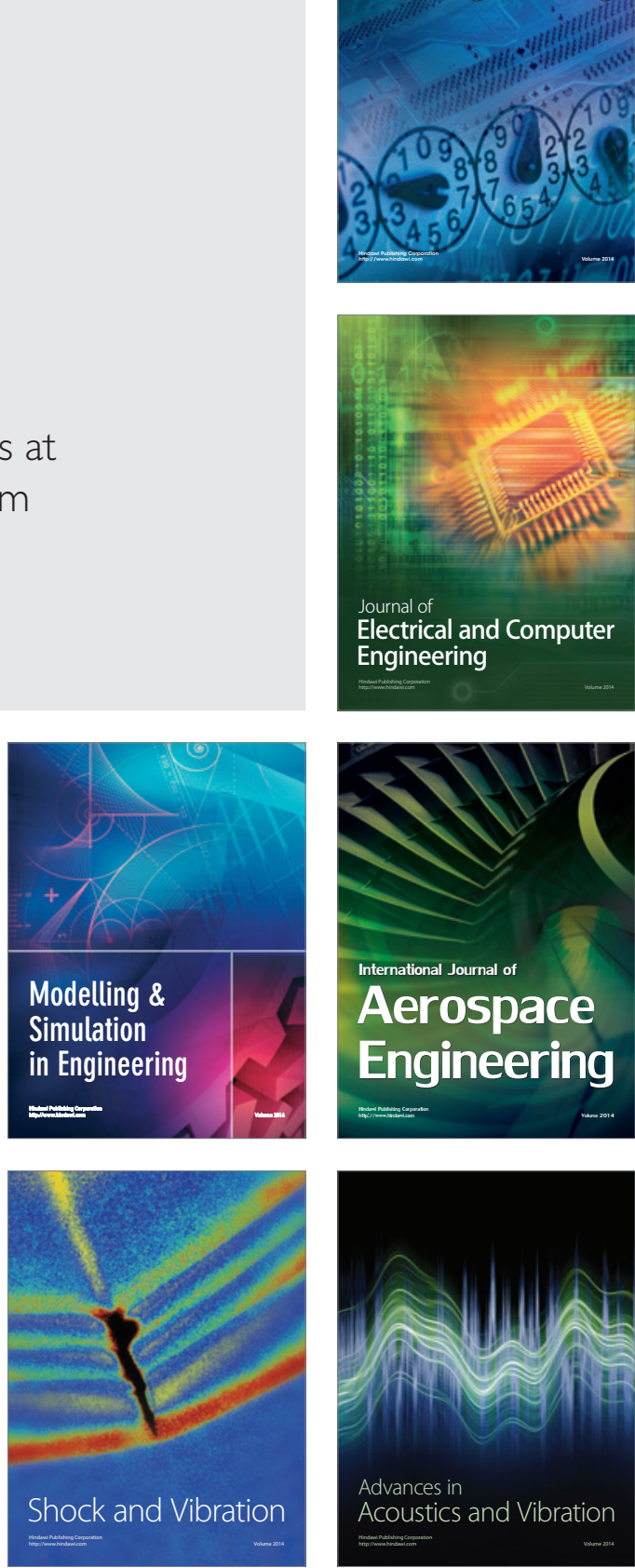